\title{
PROFIL STRENGTH OF HOPE MAHASISWA CALON GURU BK BERDASARKAN FAKTOR BUDAYA
}

\author{
Dody Hartanto ${ }^{1}$
}

\begin{abstract}
Hope is a construct that has been revealed and investigated in the process across space and time. Hope as an important aspect in the development and lives of individuals known to correlate with various factors, but have not revealed many factors related to culture, especially in Indonesia. This study aims to reveal the expectations on students of Guidance and Counseling Study Programme FKIP UAD Special Region of Yogyakarta Indonesia. The study was conducted on 123 students of VII semester consisting of 45 men and 78 women. The average age of study participants was 20-22 years old. The instrument used is the Hope Scale, shaped semantic differential scale that is composed of a large selection of 1-8 $(1=$ very inappropriate, and $8=$ very appropriate). Descriptive statistical data analysis used in this study. Results of the study showed no significant difference in the expectations of students are female than male. In the dimension measurement known student agency in Guidance and Counseling Study Programme higher than pathways dimension. Hope Sundanese cultural background of students is the highest and the lowest was followed Javanese students who have a background in Malay culture. While the expectations of the most frequently encountered are related to career, parents and self-oriented (individualism).
\end{abstract}

Keywords: Culture, Student Strength of Hope.

JOMSIGN: Journal of Multicultural Studies in Guidance and Counseling
Website : http://ejournal.upi.edu/index.php/JOMSIGN

Permalink: http://ejournal.upi.edu/index.php/JOMSIGN/article/view/6047

How to cite (APA): Hartanto, D. (2017). Profil strength of hope mahasiswa calon guru BK berdasarkan faktor budaya. JOMSIGN: Journal of Multicultural Studies in Guidance and Counseling, 1(1), 1-16.

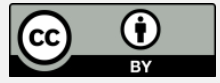

This is an open access article distributed under the terms of the Creative Commons Attribution 4.0 International License, which permits unrestricted use, distribution, and reproduction in any medium, provided the original work is properly cited.

\section{PENDAHULUAN}

Konsep harapan telah didiskusikan di berbagai tempat dan melintas batas ruang serta waktu. Meski terjadi perdebatan mengenai konsep harapan diantara para tokoh, namun terdapat satu ilustrasi yang terkenal dalam konsep harapan. Menurut Snyder (1994) ilustrasi tersebut berasal dari Yunani dan dikenal dengan dongeng kotak Pandora. Cerita bermula pada saat Prometheus yang mencuri api dari dewa, hal ini menyebabkan kemarahan dari Zeus. Selanjutnya

${ }^{1}$ Universitas Ahmad Dahlan Yogyakarta, Indonesia; dody.hartanto@bk.uad.ac.id. 
Zeus membalas dendam dengan mengirimkan gadis bernama Pandora ke bumi dengan membawa kotak yang telah diisi dengan wabah untuk memusnahkan manusia selamanya. Seperti yang diharapkan dalam rencana Zeus, Pandora tidak menaati aturan untuk tidak membuka kotak setelah tiba di bumi, pada akhirnya kekuatan jahat yang dimasukkan oleh Zeus keluar dari kotak untuk memangsa tubuh dan pikiran manusia. Menyadari hal tersebut Pandora kemudian bergegas untuk menutup kotak, dan satu-satunya kekuatan yang tersisa dari Pandora itulah yang dikenal dengan harapan. Kisah tersebut yang pada akhirnya menjadi gambaran dari perdebatan filosofis dan ilmiah.

Sepanjang kehidupan manusia teolog, filsuf, ilmuwan, dan dokter telah tertarik pada konsep harapan. Namun, pada penelitian awal tentang harapan lebih difokuskan terutama pada penyakit, baik medis dan kejiwaan. Dalam psikologi, kehilangan harapan (keputusasaan) telah ditemukan terkait (berkorelasi) dengan berkurangnya kepuasan hidup (Beck, Weissman, Lester, \& Trexler, 1974; Gottschalk, 1985; Chamodraka, 2008) dan hasil penelitian menunjukkan bahwa hilangnya harapan (hopelessness) merupakan prediktor yang lebih akurat pada kasus bunuh diri dibandingkan penyebab depresi (Beck, Steer, Kovacs, \& Garrison, 1985; Chamodraka, 2008).

Berbagai temuan yang ada, konstruk keputusasaan (hopelessness) telah berubah menjadi variabel populer dalam penelitian psikoterapi. Terlepas dari utilitas penelitian tentang hopelessness, paradigma patologis tradisional psikologi, yang "berkonsentrasi pada memperbaiki kerusakan, kesalahan, penyakit dan kekurangan dalam fungsi manusia", menyadarkan berbagai pihak bahwa kekuatan positif dari harapan dalam psikoterapi masih kurang diperhatikan (Seligman, 2000). Urgensi harapan untuk individu sebagai kekuatan hidup dinamis telah menarik perhatian para peneliti dan profesional dari berbagai disiplin selama lebih dari tiga dekade (Farran, Herth, \& Popovich, 1995; Chamodraka, 2008). Harapan pada beberapa tahun terakhir telah diidentifikasi sebagai faktor penting untuk mempromosikan kesehatan dan penyembuhan (Farran \& Popovich, 1990; Miller \& Powers, 1988; Chamodraka, 2008).

Selama tahun 1960 dan 1970-an, psikolog (Cantril, 1964; Farber, 1968; Mowrer, 1960; Stotland, 1969) dan psikiater (Frank, 1968; Melges \& Bowlby, 1969; Menninger, 1959) bersepakat bahwa pada prinsipnya harapan didasarkan pada ekspektasi positif untuk pencapaian tujuan. Selama ini, Jerome Frank dan Ezra Stotland menjelaskan pentingnya harapan bagi kesehatan mental (Frank, 1961, 1968, 1971, 1973; Stotland, 1969; Stotland \& Kobler, 1965). 
Berbagai penelitian mengenai harapan kemudian mulai dikaitkan dengan faktor budaya. Para peneliti mulai melihat pengembangan harapan dapat dan berorientasi pada cakupan praktek-praktek budaya. Berkaitan dengan masalah ini adalah salah satu pokok pemikiran yang banyak dikaji adalah perbedaan harapan pada budaya kolektif dan individualistis (Triandis et al. 1988). Penelitian tentang harapan saat ini telah melintasi berbagai budaya. Contohnya, Averill et al (1990) yang melakukan penelitian tentang makna harapan di Korea dan Amerika Serikat; (2009) penelitian Mattos tentang peran harapan dalam praktek pengajaran di Brasil; dan (2013) penelitian Cherrington dengan subyek pemuda di Afrika Selatan. Namun masih belum banyak ditemukan dalam konteks budaya di Indonesia.

Hal tersebut kemudian diperkuat dan dioperasionalisasi oleh Snyder (1994) harapan adalah pernyataan motivasional yang didapatkan dari hasil keinginan untuk sukses yang meliputi dua hal, yaitu: (1) agency (energi untuk mencapai tujuan) dan (2) pathways (rencana untuk mencapai tujuan). Teori ini telah disebarluaskan dan digunakan selama lebih dari dua dekade.

Pathways dan agency menurut (Chang \& DeSimone, 2001; Snyder, 2002; Edwards, Ong, \& Lopez, 2007). seperti dua hal yang sama namun merupakan aspek yang berbeda, dan pernyataan tersebut belum cukup dalam mendefinisikan harapan. Sementara Stotland (1969) membuat konsep harapan sebagai "an expectation greater than zero of achieving a goal" (Lopez \& Snyder, 2003). Konsep tersebut dapat dimaknai sebagai ekspektasi terhadap sesuatu yang besar untuk mencapai kerhasilan atas suatu tujuan.

Harapan harus dibedakan dengan optimisme dalam strength-based constructs (Scheier \& Carver, 1985; Edwards, Ong, \& Lopez, 2007) dan self-efficacy (Bandura, 1982; Edwards, Ong, \& Lopez, 2007). Optimisme menurut Snyder (1994) lebih berfokus pada agency (willpower), keinginan seseorang akan menjadi penentu dalam hasil serta kesuksesan di masa depan, sementara teori harapan berassumsi bahwa harus ada kesimbangan antara keinginan dengan pathways. Teori harapan berbeda dengan keyakinan diri (self efficacy) yang merefleksikan kapasitas individu dalam melakukan tindakan dengan didasarkan pada will (keinginan). Keinginan yang akan memandu seseorang dalam mencapai tujuan khusus (hanya fokus pada agency) namun tidak terlalu fokus pada pathways thinking.

Penelitian yang dilakukan oleh Magaletta and Oliver (1999) menunjukkan bahwa harapan pada individu akan memunculkan hal yang berbeda dalam 
memprediksi well being disamping optimisme dan self efficacy. Harapan dalam kajian dari Edwards (Rand, Lopez, \& Snyder, 2006; Snyder, 2002) mampu memberikan peranan yang penting dalam proses penyesuaian diri individu. Pada orang dewasa, harapan berkorelasi positif dengan psychological adjustment pada individu (Snyder, Cheavens, \& Sympson, 1997; Snyder et al, 1991; Sympson, 1999), kesehatan fisik (Barnum, Snyder, Rapoff, Mani, \& Thompson, 1998; Elliott, Witty, Herrick, \& Hoffman, 1991), serta pencapaian prestasi akademik dan hasil prestasi di bidang olah raga pada atlet (Curry, Snyder, Cook, Ruby, \& Rehm, 1997; Snyder, Sympson, Michael, \& Cheavens, 2001). Namun belum banyak ditemukan studi yang membahas mengenai harapan pada remaja. Sejumlah penelitian terbatas yang dilakukan oleh Barnum et al (Lewis \& Kliewer, 1996; Hoza, et al, 1997; Valle, Huebner, \& Suldo, 2004), mencoba untuk melihat hubungan antara harapan dengan berbagai variabel terkait dengan hasil penerimaan diri.

Penelitian tentang harapan dengan menggunakan enam item pada berbasis instrumen Children's Hope Scale (CHS; Snyder, Hoza, et al, 1997), sampel yang digunakan merupakan anak berlatar budaya Amerika Eropa. Temuan dari penelitian yang dirangkum oleh Snyder (Hoza et al, 1997) menyatakan bahwa anak dengan harapan yang tinggi diketahui memiliki tingkat depresi yang rendah dan tingkat persepsi diri yang tinggi, kemampuan atletik, penampilan fisik yang lebih terjaga, penerimaan sosial dan kompetensi akademik yang tinggi. Harapan pada penelitian lain memberikan kontribusi dalam kesehatan seorang individu. Bukti atas pernyataan tersebut adalah hasil temuan dari (Barnum et al, 1998), dikatakan bahwa seorang individu yang mengalami sakit luka bakar serius dapat lebih mudah dalam proses kesembuhannya. Hal ini berarti bahwa seorang indvidu yang mengalami penyakit, namun memiliki harapan yang tinggi akan lebih terbantu dalam proses penyembuhan yang dilakukan dengan bekerjasama bersama medis.

Penelitian dengan subyek berlatar belakang siswa keturunan Afrika Amerika telah dilakukan oleh Valle et al (2004) di Amerika. Pada penelitian tersebut hanya menguji validitas dan reliabilitas instrumen Children Hope Scale (CHS) dan didapatkan hasil validitas dan reliabilitas yang memadai. Sementara itu penelitian yang dilakukan oleh Edwards, Ong, \& Lopez (2007) kepada 135 anak keturunan Hispanik (Amerika Latin) menunjukkan bahwa skor dari Children Hope Scale (CHS) memiliki korelasi yang positif dengan kepuasan hidup, dukungan dari keluarga dan teman, serta optimisme. 
Tidak terhenti hanya di benua Amerika penelitian tentang haraoan ditemui pula di Eropa. Hal ini semakin menunjukkan arti penting dari harapan dalam kehidupan individu. Pada penelitian yang dilakukan di Ukraina pada 200 siswa di tingkat enam (masuk dalam kategori remaja) di kota Donetsk dan Lviv pada tahun 2005 menemukan bahwa harapan berkorelasi dengan enam domain aspirasi individu, dan material possessions, dan physical well-being. Sementara penelitian yang dilakukan di Portugal oleh Susana C. Marques et al (2014) pada 1,012 siswa SMA mendapati hasil validitas dan reliabilitas dari penggunaan skala Harapan dari Snyder dapat digunakan pada siswa berlatar belakang Portugal.

Penelitian tentang harapan dilakukan pula oleh Shazly Savahl (2013) di Afrika Selatan pada 566 remaja berusia 14-17 tahun di kota Cape Town. Penelitian ini mengeksplorasi hubungan antara community violence, hope, dan well-being. Hasil dari penelitian ini adalah terdapat hubungan yang positif antara harapan pada anak dengan well-being.

Penelitian tentang harapan di benua Asia sendiri telah dilakukan, seperti di Korea dan Filipina. Penelitian di Filipina tentang harapan dilakukan oleh Allan B. I. Bernardo dan Alicia F. Estrellado (2014) dan baru terbatas pada mengujicobakan instrumen Hope khususnya bagi individu yang memiliki tingkat pendidikan rendah (diketahui penelitian ini berusaha mengungkap hasil skala setelah diadaptasi dalam bahasa Filipina). Penelitian ini berfokus pada oorang dewasa, dan dilakukan pada 362 orang yang berusia 18 hingga 60 tahun. Sementara itu studi yang dilakukan di Korea Selatan oleh Tack-Ho Kim et al (2005) kepada 2,677 siswa ditemukan bahwa harapan, dukungan guru, berpengaruh secara signifikan dalam meningkatkan resiliensi anak terhadap perilaku maladaptif dalam kelompok, khususnya di sekolah. Studi lain dalam jumlah yang lebih besar dilakukan di Minesota pada 36,549 siswa di tingkat enam, sembilan dan duabelas. Penelitian ini meneliti hubungan antara harapan dan kekerasan, dan komparasi harapan berdasarkan jenis kelamin dan etnis.

Berdasarkan paparan dan berbagai penelitian yang dilakukan tersebut dapat dipahami bahwa harapan merupakan aspek penting dalam perkembangan dan kehidupan individu. Berbagai penelitian telah dilakukan di berbagai negara lain namun, masih belum diarahkan pada penelitian pada setting di Indonesia dengan melihat latar belakang budaya dari partisipan. Penelitian juga belum banyak yang mengungkap harapan berdasarkan jenis kelamin. Penelitian harapan 
berdasar jenis kelamin diantaranya ditemukan dalam studi yang dilakukan oleh Snyder (Hoza, et al., 1997; Valle et al., 2004).

Tujuan dari penelitian ini adalah untuk melakukan studi yang sistematis tentang profil strength of hope mahasiswa berdasarkan faktor demografi pada mahasiswa di Program Studi Bimbingan dan Konseling FKIP UAD, dan spesifik pada: a) Harapan berdasarkan aspek pathways dan agency, b). Harapan berdasarkan jenis kelamin, dan c). Perbedaan harapan berdasarkan latar belakang budaya mahasiswa.

\section{METODE}

Penelitian ini menggunakan desain kuantitatif jenis survei analitik. Penelitian survei yang dilakukan ini termasuk dalam survey cross sectional yaitu penelitian untuk mempelajari dinamika kolerasi antara faktor-faktor sebab dengan akibat. Penelitian ini dilakukan pada mahasiswa semester 7 (tingkat akhir) di Kota Yogyakarta Propinsi Daerah Istimewa Yogyakarta. Survey dilakukan dengan menggunakan instrumen Skala Harapan yang telah diadaptasi dan dimodifikasi berbahasa Indonesia. Survey dilakukan berdasarkan dua latar belakang demografi yaitu: jenis kelamin dan latar belakang budaya. Analisis deskriptif dilakukan pasca survey yang dilakukan di ruang kelas dan dalam waktu bersamaan. Pengumpulan data pada penelitian ini dilakukan secara bersama sama. Partisipan penelitian ini berjumlah 123 mahasiswa di Program Studi Bimbingan dan Konseling Fakultas Keguruan dan Ilmu Pendidikan Universitas Ahmad Dahlan Yogyakarta, Indonesia, yang terdiri atas 45 laki-laki dan 78 perempuan. Rata-rata usia dari partisipan studi ini adalah 20-22 tahun. Pemilihan Mahasiswa Aktif pada semester ke tujuh (VII) didasarkan pada asumsi bahwa pada usia tersebut partisipan berada dalam posisi dewasa awal dan peralihan dari usia pendidikan menuju usia karir.

Latar Belakang budaya dari partisipan dapat dikelompokkan ke dalam tiga yaitu: 1) Jawa, 2). Sunda dan 3). Melayu. Instrumen dalam penelitian ini merupakan hasil adaptasi dan modifikasi dari The Future Scale (Snyder \& Harris, 1991) yang terdiri atas 12 item dan digunakan pada remaja usia 15 tahun ke atas. Didasarkan pada pengembangan teori Harapan dari Snyder. 12 item yang ada pada skala terbagi atas 4 item untuk mengukur pathways atau dikenal dengan waypower, 4 item untuk mengukur agency (willpower) dan 4 item pengecoh. Skala menggunakan bentuk skala semantik diferensial yang tersusun 
atas pilihan 1-8 (1 = sangat tidak sesuai, dan $8=$ sangat sesuai). Skala Harapan hasil adaptasi dan modifikasi yang digunakan telah terlebih dahulu diuji validitas dan reliabilitas. Pengembangan instrumen melibatkan penilaian ahli dari Bidang Bahasa (Inggris dan Indonesia) untuk menguatkan struktur dalam setiap butir pertanyaan. Sementara itu, untuk menguatkan konsep atribut harapan dilakukan uji ahli materi dari Bidang Bimbingan dan Konseling. Hal tersebut dilakukan untuk memperoleh hasil yang memadai dalam pengumpulan data. Hasil dari ujicoba terhadap instrumen menyatakan bahwa keduabelas item pada Skala Harapan valid dan reliabel untuk digunakan.

Penentuan partisipan dilakukan dengan cara random. Pada proses pengumpulan data untuk menghindari faking dan guesing, maka mahasiswa dipandu dalam pengisian. Studi ini menggunakan analisis statistik deskriptif. Untuk mengetahui hasil dari harapan pada siswa khususnya pada dimensi pathways dan agency digunakan analisis varian satu jalur (one way Anova). Uji t dan anova digunakan untuk membantu mengetahui perbedaan harapan antara jenis kelamin laki-laki dan perempuan serta untuk mengetahui perbedaan rata-rata harapan berdasarkan belakang budaya mahasiswa.

\section{HASIL DAN PEMBAHASAN}

Secara umum data harapan yang dimiliki oleh mahasiswa Semester VII Program Studi Bimbingan dan Konseling FKIP UAD disajikan pada Tabel 1. Hasil penelitian menunjukkan bahwa pada dua aspek harapan yang dimiliki, diketahui agency mahasiswa lebih tinggi dibandingkan pathways. Artinya mahasiswa lebih memiliki keinginan (willpower) namun tidak memiki rencana untuk mencapai tujuan (agency) yang lebih baik. Sementara itu, hasil uji statistik secara lebih detail menunjukkan tidak ada perbedaan harapan baik pada aspek pathways dan agency ditilik dari jenis kelamin.

Berdasarkan analisis hasil perhitungan diketahui bahwa mahasiswa dengan latar belakang Sunda memiliki Pathways dan Agency yang lebih tinggi dibandingkan mahasiswa dengan latar belakang suku Jawa dan paling rendah adalah dari suku Melayu. Meskipun terlihat hampir tidak ada perbedaan, namun nilai aspek agency pada laki-laki dengan latar belakang Sunda lebih tinggi dibanding perempuan, yaitu sejumlah 27.44 dan pada perempuan sebesar 25.63.

Pada bagian hasil naratif yang dituliskan oleh mahasiswa semua menuliskan harapan merupakan aspek penting dalam kehidupan mereka. Harapan yang 
dimiliki mahasiswa terarah pada diri pribadi (nilai memuaskan, lulus, menikah, studi lanjut), pekerjaan (karir) dan orang tua, namun kesemuanya masih dominan pada berorientasi diri pribadi.

Tabel 1. Hasil Perhitungan Harapan Pada Mahasiswa Semester VII Program Studi Bimbingan dan Konseling FKIP UAD

\begin{tabular}{|c|c|c|c|c|c|}
\hline & JK & Ras & Mean & Std. Deviation & $\mathrm{N}$ \\
\hline \multirow[t]{12}{*}{ Pathways } & \multirow[t]{4}{*}{1} & 1 & 25.20 & 3.500 & 25 \\
\hline & & 2 & 25.89 & 3.655 & 9 \\
\hline & & 3 & 23.27 & 4.245 & 11 \\
\hline & & Total & 24.87 & 3.757 & 45 \\
\hline & \multirow[t]{4}{*}{2} & 1 & 23.40 & 3.201 & 42 \\
\hline & & $\overline{2}$ & 24.16 & 2.986 & 19 \\
\hline & & 3 & 23.35 & 2.621 & 17 \\
\hline & & Total & 23.58 & 3.013 & 78 \\
\hline & \multirow[t]{4}{*}{ Total } & 1 & 24.07 & 3.404 & 67 \\
\hline & & 2 & 24.71 & 3.253 & 28 \\
\hline & & 3 & 23.32 & 3.278 & 28 \\
\hline & & Total & 24.05 & 3.348 & 123 \\
\hline \multirow[t]{12}{*}{ Agency } & \multirow[t]{4}{*}{1} & 1 & 26.56 & 3.110 & 25 \\
\hline & & 2 & 27.44 & 3.127 & 9 \\
\hline & & 3 & 24.09 & 2.809 & 11 \\
\hline & & Total & 26.13 & 3.216 & 45 \\
\hline & \multirow[t]{4}{*}{2} & 1 & 25.05 & 3.305 & 42 \\
\hline & & 2 & 25.63 & 3.419 & 19 \\
\hline & & 3 & 24.24 & 3.270 & 17 \\
\hline & & Total & 25.01 & 3.317 & 78 \\
\hline & \multirow[t]{4}{*}{ Total } & 1 & 25.61 & 3.293 & 67 \\
\hline & & 2 & 26.21 & 3.381 & 28 \\
\hline & & 3 & 24.18 & 3.044 & 28 \\
\hline & & Total & 25.42 & 3.312 & 123 \\
\hline
\end{tabular}

Harapan merupakan konstruk psikologi yang menarik untuk terus diteliti. Harapan dimaknai sebagai konsep kunci dalam pencapaian tujuan dan kesuksesan hidup individu. Berbagai penelitian telah dilakukan dalam berbagai setting dan atribut psikologis yang menyertai. Penelitian yang dilakukan pada mahasiswa (dewasa awal) di Program Studi Bimbingan dan Konseling Universitas Ahmad Dahlan menunjukkan dimensi agency pada siswa berjenis kelamin laki-laki lebih baik dibandingkan perempuan. Sementara harapan 
mahasiswa dengan latar belakang budaya Sunda adalah yang tertinggi dibandingkan mahasiswa dengan latar belakang budaya Jawa dan Melayu.

Hasil penelitian ini bertolak belakang dengan hasil penelitian yang telah dilakukan peneliti pada tahun 2015 dengan subyek remaja (SMA) di Yogyakarta. Pada hasil penelitian di tahun 2015 diketahui dimensi pathways remaja lebih baik dibandingkan agency. Artinya remaja lebih memiliki rencana untuk mencapai tujuan namun tidak memiki keinginan (willpower) yang lebih baik. Kesamaan hasil penelitian pada 2015 dan 2016 yang dilakukan oleh peneliti adalah pada dimensi agency jenis kelamin laki-laki lebih tinggi dibanding perempuan.

Hasil analisis yang dilakukan oleh Gallup Student Poll pada tahun dan dilakukan oleh Lopez et al (Callina et al., 2014), melalui metode survey kepada tidak kurang dari 240.000 anak di tingkat 5 sampai tingkat 12 menunjukkan bahwa harapan berkorelasi kuat dengan indikator self efficacy, self-regulation, dan well-being. Harapan juga pada akhirnya dapat mempengaruhi kesuksesan akademik, kemampuan akademik dan prestasi di bidang olah raga remaja di sekolah.

Harapan diketahui juga berkorelasi dengan kebahagiaan hidup individu. Berdasarkan data dari Perserikatan Bangsa-Bangsa (PBB) melansir survei indeks kebahagiaan dunia untuk 2016. Lembaga internasional ini mengukur tingkat kebahagiaan warga di 157 negara. Hasilnya, posisi Indonesia melorot lima peringkat dibanding survei 2015, yaitu berada di urutan 79 dunia. Posisi kebahagiaan penduduk Indonesia tersebut lebih rendah dibanding Singapura (22), Thailand (33) atau Malaysia (49). Bahkan lebih rendah dari negara yang terkoyak perang saudara seperti Somalia (76). Hasil penelitian yang dilakukan Emily E. Haroz et al (2015) dengan membandingkan keadaan di tiga negara yaitu: Burundi, Nepal dan Indonesia. Diketahui bahwa harapan pada anak-anak di Indonesia masih lebih tinggi dibandingkan dengan dua negara lain. Sementara Nepal memiliki anak-anak yang memiliki harapan lebih rendah dibandingkan dengan di Burundi. Penelitian Emily yang memaparkan tentang harapan tersebut masih belum melihat dimensi dari harapan secara utuh. Partisipan pada penelitian yang dilakukan di Indonesia mengambil setting tempat di Poso Sulawesi. Daerah Poso merupakan daerah yang pernah mengalami konflik agama. Hasil penelitian ini juga sama dengan hasil penelitian yang dilakukan Emily E. Haroz et al (2015). Penelitian dilakukan dengan mengkomparasikan tiga negara yaitu: Indonesia, Nepal dan Burundi. 
Partisipan penelitian berjumlah 1,057; (48 \% perempuan), terbagi dalam 329 Burundi; 403 Indonesia; 325 Nepal. menunjukkan bahwa harapan individu berjenis kelamin laki-laki di Indonesia lebih tinggi dibandingkan dengan perempuan. Temuan penelitian tersebut juga menyatakan bahwa harapan di negara Burundi dan Nepal lebih pada anak berjenis kelamin laki-laki dibandingkan dengan perempuan. Pada berbagai temuan kasus hasil praktik yang dilakukan oleh Snyder (1994) banyak individu yang memiliki banyak sekali rencana dalam kehidupan, namun minim akan keinginan. Hal ini dipengaruhi multi demensional faktor dan bukan hanya faktor tunggal.

Hasil penelitian yang didapatkan ini sama dengan hasil penelitian dari Sharon Danoff-Burg (2004) pada 100 mahasiswa berkulit hitam di Amerika (40 perempuan dan 60 laki-laki) dari usia 17 sampai dengan $32(\mathrm{M}=19.14, \mathrm{SD}=$ 2.22) mendapatkan hasil agency yang lebih tinggi dibandingkan dengan pathways.

Hasil penelitian dengan tema harapan yang dilakukan di Tanzania pada siswa berusia 12 sampai dengan 18 tahun, mendapatkan hasil yang juga berbeda dengan hasil penelitian ini. Hasil dari harapan remaja di Tanzania menunjukkan hasil patways yang lebih baik dibandingkan agency. Penelitian tersebut dilakukan oleh Priya G Nalkur di tahun 2009 dengan setting di luar Amerika dan Eropa.

Sementara itu, hasil yang didapatkan dari penelitian ini juga sama dengan dengan penelitian yang dilakukan oleh Detris Honora Adelabu (2008) terhadap 661 remaja dengan latar belakang Afrika Amerika. Diketahui bahwa hasil dari dimensi Agency dengan means sebesar 13.4 dan SD 1.8, sementara Pathways diketahui memiliki means 12.8 dan SD 1.7. Hal ini menunjukkan bahwa nilai willpower yang dimiliki remaja lebih tinggi dibandingkan waypower.

Hasil penelitian ini sangat sejalan dengn paparan teori dari Snyder (1994) pada dasarnya tidak terdapat perbedaan antara laki-laki dengan perempuan dalam harapan. Akan tetapi akan terdapat banyak faktor yang kemudian akan mempengaruhi berkembangan harapan pada individu. Faktor keluarga dalam hal ini orang tua, lingkungan tempat tinggal, sekolah, teman, pendidikan dan juga aspek kepribadian dari individu akan mendorong perolehan dan perkembangan harapan.

Menurut Snyder harapan merupakan hasil kalkulasi dari interaksi yang dilakukan oleh anak dengan pengasuh, teman sebaya dan guru. Snyder; Hoza., 
et al (1997) menjelaskan bahwa tinggi rendahnya harapan dapat dipengaruhi oleh kontak individu dengan orang lain. Selain itu Taylor (1989) menyatakan bahwa harapan dipengaruhi pula oleh kemampuan adaptive coping style. Penelitian lain yang dilakukan oleh (Snyder, Harris, et al., 1991; Snyder, Hoza., et al (1997) juga menemukan Harapan memiliki korelasi yang positif dengan sifat sosial dan positive self-presentation. Tinggi dan rendahnya harapan dalam penelitian yang dilakukan oleh Barnum et al (Snyder 1994) dipengaruhi oleh dukungan sosial. Sementara itu harapan dalam penelitian Hoza, et al (1997) diketahui memiliki korelasi dengan kompetensi sosial yang dimiliki oleh individu. Semakin baik kompetensi sosial individu semakin tinggi harapan yang dimiliki. Oleh karenanya, dalam pandangan Staats (Snyder, 2003) diperlukan pengukuran yang tidak hanya menggunakan pendekatan kuantitatif, namun dapat dilengkapi dengan pendekatan yang bersifat kualitatif, dan menyebutnya sebagai pendekatan terintegrasi.

Berdasarkan pendapat dari Staats tersebut maka peneliti berusaha mengungkap arah harapan dari mahasiswa secara deskriptif singkat. Hasil penelitian menunjukkan bahwa mahasiswa memiliki harapan agar bisa segera menyelesaikan studi, dan bekerja. Harapan lain yang dimiliki oleh mahasiswa adalah terkait dengan karir dimasa depan dan kesuksesan serta kebahagiaan dari orang tua. Hasil data kualitatif tersebut berbeda hasilnya dengan penelitian pada para imigran Meksiko. Hasil penelitian Gariglietti (Lopez \& Snyder, 2004) menunjukkan hubungan antara harapan dan penyesuaian sosial, prestasi akademis, dan kemampuan bahasa anak-anak imigran. Temuan utama adalah bahwa harapan berkorelasi positif dengan penyesuaian siswa dan kemampuan berbahasa. Hasil penelitian juga melaporkan perbedaan gender, yang belum ditemukan dalam penelitian harapan sebelumnya. Dimana hasilnya imigran perempuan (usia 8 sampai 16) memiliki tingkat harapan lebih tinggi daripada laki-laki.

Penelitian harapan berbasis budaya lain dilakukan oleh Turner (Lopez \& Snyder, 2004) menghasilkan temuan bahwa harapan keanggotaan dalam kelompok sosial akan berhubungan dengan harapan memiliki korelasi positif dan signifikan dengan budaya dan agama yang mereka anut. SEmentara itu, penelitian dengan latar budaya Afrika Amerika memiliki akar agama yang kuat. Hasil penelitian Sherwin (Lopez \& Snyder, 2004) menemukan bahwa harapan pada anak-anak keturunan Afrika Amerika berhubungan positif (1) ekspresi 
positif, komitmen realistis untuk kelompok sendiri, dan (2) orientasi religius dan spiritual sebagai individu dengan budaya Afrika Amerika.

Penelitian yang mencoba membandingkan harapan berdasarkan jenis kelamin telah banyak dilakukan. Budaya diketahui memegang peranan dalam nilai-nilai yang berbeda dan bahwa tujuan individu akan terikat dengan nilai-nilai, mengetahui tujuan dari klien dapat memfasilitasi pemahaman yang lebih baik dari harapan mereka. Dibandingkan dengan pandangan tradisional, model perilaku multikultural menawarkan perspektif yang berbeda dan lebih radikal dalam pengembangan teori harapan (Elliott \& Sherwin, 1997). Harapan dapat tertanam dalam proses sosial-kognitif, seperti Snyder et al (1997) budaya dapat "mempengaruhi cara manusia memilih, menafsirkan, proses, dan menggunakan informasi" (Kluckhohn, 1954; Triandis, 1994). Masyarakat kolektif menekankan pentingnya kelompok dan nilai-nilainya, kegiatan, dan peran atas kegiatan independen dan prestasi yang merupakan ciri khas dari masyarakat individualistis. Selain itu, individu dengan sikap kolektivis cenderung lebih peka terhadap efek eksternal, mendalam, dan situasional terhadap perilaku pribadi, dengan sesuai perbedaan keyakinan mengenai kesehatan pribadi, penyesuaian, dan tanggung jawab (Landrine, 1992; Landrine \& Klonoff, 1992).

Hasil temuan dari penelitian ini tidak bertentangan dengan teori awal yang dibangun oleh Snyder (1994) yang menyatakan tidak terdapat perbedaan harapan antara laki-laki dengan perempuan. Akan tetapi hal tersebut dapat dipahami, karena selama proses perkembangan anak akan menemui lingkungan dan mendapat pengasuhan yang berbeda.

Pada remaja dengan jenis kelamin perempuan didapatkan hasil mean sebesar 3.05 semntara pada laki-laki didapatkan hasil 2.87. Sementara itu, penelitian yang dilakukan oleh Kemer, G., \& Atik, G. (2012) di Turki pada 737 (407 perempuan dan 330 laki-laki) dari dua sekolah daerah urban dan rural di Kota Ankara dengan tema harapan siswa ditilik dari cinta, esteem-related support, instrumental support, dan jenis kelamin. Informasi menarik dari penelitian tersebut yang dikaitkan dengan penelitian ini adalah bahwa pada anak laki-laki lebih didapati memiliki kontribusi positif dalam harapan. Artinya anak laki-laki di kawasan urban lebih memiliki harapan dibanding perempuan.

Hal penelitian di tingkat mahasiswa sama dengan penelitian yang dilakukan di negara Amerika. Hasil penelitian lain yang dilakukan di Amerika oleh Snyder (2000), siswa laki-laki diketahui memiliki harapan yang lebih tinggi dibandingkan perempuan. Hal ini menjadi kajian yang menarik karena jika 
dikaitkan dengan budaya remaja laki-laki di Turki lebih memiliki keleluasaan dibandingkan perempuan dalam berbagai hal. Nurmi \& Pulliainen (Callina et al., 2014) menyatakan bahwa pengasuhan oleh orang tua secara langsung akan memberi pengaruh pada harapan remaja di masa yang akan datang serta periode yang berbeda antara satu dengan yang lain. Hubungan antara orang tua dan anak pada akhirnya menurut Erikson (1959; Flanagan, 2003; Callina et al., 2014) akan memperkuat harapan dan meningkatkan kepercayaan pada anak.

Hasil penelitian yang dilakukan Allan B. I. Bernardo (2014) menunjukkan bahwa orang tua di Filipina yang memiliki kecenderungan budaya kolektivisme berkorelasi dengan harapan yang dimiliki anak. Penelitian ini dilakukan pada 362 partisipan yang terbagi dalam 241 perempuan dan 104 laki-laki di Metro Manila. Terdapat kesamaan konteks antara Indonesia dan Filipina yang memiliki budaya kolektivisme. Hasil penelitian yang telah dilakukan menunjukkan bahwa orang tua siswa yang memiliki kecenderungan budaya kolektivisme akan mendorong harapan pada anak.

Terdapat beberapa hal penting yang menjadi catatan dan keterbatasan dalam penelitian ini. Pertama, jumlah partisipan yang digunakan jumlahnya perlu untuk ditingkatkan karena hanya berasal dari satu program studi dan pada satu universitas di DIY. Kedua, partisipan masih terbatas pada siswa dengan latar belakang tiga budaya di Indonesia, yaitu Jawa Sunda dan Melayu dan satu agama (Islam), sehingga masih dapat dilakukan penelitian lain dengan latar belakang budaya berbeda (multikulture) dan agama lain. Ketiga, instrumen yang digunakan dengan model skala semantik diferensial perlu untuk disesuaikan dengan konteks budaya tempat pengambilan data. Terakhir penelitian dapat diarahkan pada aspek demografi lain seperti latar belakang pekerjaan orang tua, latar belakang pendidikan orang tua, dukungan orang tua, agama dan kepercayaan yang dianut siswa.

\section{SIMPULAN}

Berdasarkan hasil penelitian, diskusi dan keterbatasan yang didapatkan, proses penelitian di masa yang akan datang dapat diarahkan pada beberapa latar belakang demografi terkait dengan orang tua (pendidikan, status pernikahan, agama dan kepercayaan, serta tingkat ekonomi). Jenis penelitian dapat pula dikembangkan melalui studi survey dengan desain kualitatif melalui metode pengumpulan data berbasis wawancara mendalam. Pada akhirnya diperlukan 
pula penelitian mengenai harapan pada anak-anak dan remaja serta orang tua untuk melengkapi hasil penelitian yang ini. Hasil penelitian menunjukkan bahwa harapan pada setiap individu merupakan atribut yang unik, dimana antara satu individu dengan individu yang lain memiliki perbedaan. Perbedaan dapat dilihat dari berbagai latar belakang demografi yang melekat pada diri individu. Hasil penelitian ini menunjukkan dimensi agency harapan mahasiswa laki-laki lebih tinggi dibandingkan pada perempuan. Sementara itu, latar belakang budaya Sunda diketahui menjadi peraih harapan tertinggi dan disusul Jawa serta Melayu.

\section{REFERENSI}

Adelabu, D. H. (2008). Future time perspective, hope, and ethnic identity among African American adolescents. Urban Education, 43(3), 347-360.

Bernardo, A. B. (2015). Hope in early adolescence: measuring internal and external locus-of-hope. Child Indicators Research, 8(3), 699-715.

Callina, K. S., Johnson, S. K., Buckingham, M. H., \& Lerner, R. M. (2014). Hope in context: Developmental profiles of trust, hopeful future expectations, and civic engagement across adolescence. Journal of youth and adolescence, 43(6), 869-883.

Chamodraka, M. (2008). Hope development in psychotherapy: a grounded theory analysis of client experiences. Dissertation: McGill University.

Charles, C. (2009). The ecology of hope: Natural guides to building a children and nature movement. Journal of Science Education and Technology, 18(6), 467-475.

Chui, W. H., \& Wong, M. Y. (2015). Association Between Parents' Marital Status and the Development of Purpose, Hope, and Self-Esteem in Adolescents in Hong Kong. Journal of Family Issues, 1-19.

Danoff-Burg, S., Prelow, H. M., \& Swenson, R. R. (2004). Hope and life satisfaction in Black college students coping with race-related stress. Journal of Black Psychology, 30(2), 208-228.

Diko, N. (2014). Women in educational leadership: the case of Hope High School in the Eastern Cape Province, South Africa. Educational Management Administration \& Leadership, 42(6), 825-834.

Edwards, L. M., Ong, A. D., \& Lopez, S. J. (2007). Hope measurement in Mexican American youth. Hispanic Journal of Behavioral Sciences, 29(2), 225-241. 
Giroux, H. A. (1997). Pedagogy and the Politics of Hope Theory, Culture, and Schooling: A Critical Reader. USA: Wesmievv Press.

Halfond, R., Corona, R., \& Moon, A. (2013). Latino parent and adolescent perceptions of hoped-for and feared possible selves for adolescents. Journal of Adolescent Research, 28(2), 209-240.

Halpin, D. (2003). Hope and education: The role of the utopian imagination. New York: Taylor \& Francis e-Library.

Hochheimer, J. L. (2009). Communication education and the human spirit: Notes toward a pedagogy of hope. Hope in the 21st century, 113-139.

Howell, A. J., \& Larsen, D. J. (2015). Understanding Other-Oriented Hope: An Integral Concept Within Hope Studies. Springer.

Kemer, G., \& Atik, G. (2012). Hope and social support in high school students from urban and rural areas of Ankara, Turkey. Journal of Happiness Studies, 13(5), 901-911.

Kim, T. H., Lee, S. M., Yu, K., Lee, S., \& Puig, A. (2005). Hope and the meaning of life as influences on Korean adolescents' resilience: Implications for counselors. Asia Pacific Education Review, 6(2), 143152.

Lopez, S. J., \& Snyder, C. R. (Eds.). (2004). Positive psychological assessment: A handbook of models and measures. Washington, DC: American Psychological Association.

Marques, S. C., Lopez, S. J., \& Pais-Ribeiro, J. L. (2011). "Building hope for the future": A program to foster strengths in middle-school students. Journal of Happiness Studies, 12(1), 139-152.

McCoy, H., \& Bowen, E. A. (2015). Hope in the social environment: factors affecting future aspirations and school self-efficacy for youth in urban environments. Child and Adolescent Social Work Journal, 32(2), 131-141.

Nalkur, P. G. (2009). Adolescent hopefulness in Tanzania: Street youth, former street youth, and school youth. Journal of Adolescent Research, 24(6), 668-690.

Nikolayenko, O. (2011). Adolescents' hopes for personal, local, and global future: Insights from Ukraine. Youth \& Society, 43(1), 64-89.

O'Sullivan, G. (2011). The relationship between hope, eustress, self-efficacy, and life satisfaction among undergraduates. Social indicators research, 101(1), 155-172. 
Padilla-Walker, L. M., Hardy, S. A., \& Christensen, K. J. (2011). Adolescent hope as a mediator between parent-child connectedness and adolescent outcomes. The Journal of Early Adolescence, 31(6), 853-879.

Peterson, C., \& Seligman, M. E. (2004). Character strengths and virtues: A handbook and classification (Vol. 1). Oxford University Press.

Snyder, C. R. (1994). The psychology of hope: You can get there from here. New York: Simon and Schuster.

Snyder, C. R. (Ed.). (2000). Handbook of hope: Theory, measures, and applications. USA: Academic Press.

Valero, D., Hirschi, A., \& Strauss, K. (2015). Hope in adolescent careers: Mediating effects of work motivation on career outcomes in Swiss apprentices. Journal of Career Development, 42(5), 381-395.

Waterworth, J. (2004). A philosophical analysis of hope. New York. Palgrave.

Wise, A. (2005). Hope and belonging in a multicultural suburb. Journal of intercultural studies, 26(1-2), 171-186..

Yahya, H. (2003). Hopefulness In The Qur'an. Malaysia: Saba Islamic Media

Yarcheski, A., \& Mahon, N. E. (2016). Meta-analyses of predictors of hope in adolescents. Western journal of nursing research, 38(3), 345-368.

Yakushko, O., \& Sokolova, O. (2010). Work hope and influences of the career development among Ukrainian college students. Journal of Career Development, 36(4), 310-323. 